\title{
Exercise and Training to Optimize Functional Motor Performance in Stroke: Driving Neural Reorganization?
}

\author{
Roberta B. Shepherd \\ School of Physiotherapy, Faculty of Health Sciences, The University of Sydney, Australia
}

\begin{abstract}
SUMMARY
Neurorehabilitation is increasingly taking account of scientific findings. Research areas directing stroke rehabilitation are neurophysiology; adaptability to use and activity; biomechanics; skill learning; and exercise science (task, context specificity). Understanding impairments and adaptations enables a reappraisal of interventions-for example, changes in motor control resulting from impairments (decreased descending inputs, reduced motor unit synchronization), secondary soft tissue changes (muscle length and stiffness changes) are adaptations to lesion and disuse. Changes in interventions include increasing emphasis on active exercise and task-specific training, active and passive methods of preserving muscle extensibility. Training has the potential to drive brain reorganization and to optimize functional performance. Research drives the development of training programs, and therapists are relying less on one-to-one, hands-on service delivery, making use of circuit training and group exercise and of technological advances (interactive computerized systems, treadmills) which increase time spent in active practice. Emphasis is on skill training, stressing
\end{abstract}

\footnotetext{
${ }^{\dagger}$ Mailing address:

22 Albion Street, Waverley

NSW 2024 AUSTRALIA

fax: 61293865386

e-mail: R.Shepherd@cchs.usyd.edu.au
}

cognitive engagement and practice, aiming to increase strength, control, skill, endurance, fitness, and social readjustment. Rehabilitation services remain slow to make the changes necessary to upgrade environments, attitudes, and rehabilitation methodologies to those shown to be more scientifically rational and for which there is evidence of effectiveness.

\section{KEYWORDS}

CVA, physiotherapy, task-specificity, exercise, training, brain reorganization

\section{INTRODUCTION}

This paper briefly describes a perspective in movement rehabilitation following brain lesion which has been in development over the past 15 years (e.g., Carr \& Shepherd, 1998; 2000). It is a perspective to which many have contributed since it has developed out of investigations in the fields of motor control, motor learning; biomechanics; cognitive, behavioral, and environmental psychology; neural plasticity; and neuropathology. It is based on the view that the methods used in movement rehabilitation should be based in science (particularly in the sciences related to human movement), updated as scientific understanding advances and based on evidence of effectiveness. It remains the case, however, that much of what is currently done in the name of movement rehabilitation still does 
not meet these requirements but is based on unproved, untested concepts, and/or the personal preferences of therapists and physicians. There seems a reluctance in some centers to push for the major changes which need to be made, both to the process of neurorehabilitation and to the environment in which it is carried out, if neurorehabilitation is to be optimally restorative and if it is to be time and cost efficient.

There is increasing evidence on the effectiveness of many newer methods of intervention, developed out of recent scientific investigations and focusing particularly on task-specific exercise and training. There is also evidence that training methods designed to stimulate motor learning can have positive effects on brain reorganization after a neural lesion. In this paper it is argued that there are at least five major areas of scientific research, the recent findings of which are driving these more effective rehabilitation methods:

- Mechanisms of primary impairments underlying the neural lesion.

- Adaptive nature of the neuromuscular systems in response to use/activity and experience.

- Biomechanics and neural control of human movement.

- Mechanisms of motor skill learning and the critical importance of practice.

- Exercise science: task and context specificity of neuromuscular action and therefore of exercise and training.

\section{PRIMARY IMPAIRMENTS AND ADAPTATIONS AFTER STROKE}

It is common in stroke for there to be involvement of the cortically-originating motor system-the upper motor neuron (UMN), its pathways, and connections. Since Hughlings Jackson, it has been typical to consider the impairments that are associated with the UMN syndrome as positive and negative, the positive referring to exaggerations of normal phenomena, the negative to features such as impairments in muscle activation and motor control. A major negative feature, weakness, is due to loss of motor unit activation, changes in recruitment ordering, and changes in firing rates (Tang \& Rymer, 1981; Dietz et al., 1986). Weakness from these sources is compounded by changes in the properties of motor units and in morphological and mechanical changes in the muscles which occur adaptively as a consequence of denervation, but also of decreased physical activity and disuse (e.g., Farmer et al., 1993; McComas, 1993). Muscle weakness and disordered motor control combine to cause functional movement disability.

This division still has explanatory value for clinical practice, although current research suggests the classification may be an oversimplification. However, working within this framework, it is useful to include a third set of characteristics called adaptive (Carr \& Shepherd, 1998; 2000). It appears likely that some of the features which have been considered positive (e.g., hypertonus and abnormal movement patterns) are more likely to be the result of the adaptation of neural system, muscles, and soft tissues to the primary impairments (Fig. 1).

Inclusion of this additional characteristic is useful because clarification of the mechanisms underlying functional deficits is crucial to the development of rehabilitation methods and the planning of rehabilitation environments. Some of the confusion in clinical practice is to due to the use of confusing terminology. The term 'spasticity' is used generically to cover both neural and muscle changes, despite the fact that it was defined at a neurological consensus conference in the 1980s as velocity-dependent hyperactivity of tonic stretch/ proprioceptive reflexes (Lance, 1980; 1990).

Similarly, the term 'hypertonus' (evaluated by the degree of resistance to passive movement) suggests an underlying neural origin, yet it appears that the resistance is largely due to changes in 


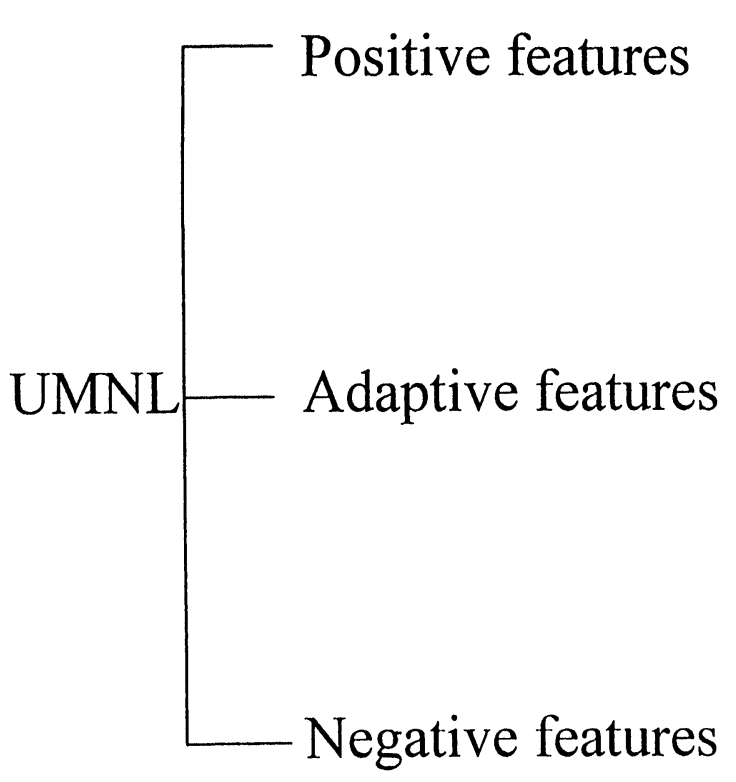

Hyperreflexia

(spasticity)

$?$
$\downarrow$
Muscle + connective tissue changes

(altered mechanical and functional properties)

Hypertonus (resistance to passive movement)

Altered motor patterns

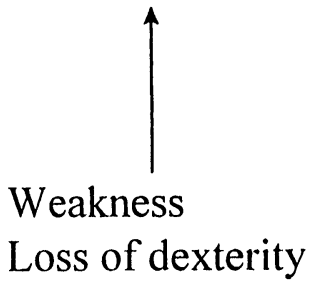

Fig. 1: The positive, negative and adaptive features following UMN lesion

muscle and connective tissue (increased stiffness and other length and disuse-associated changes), with the contribution of hyperreflexia remaining equivocal.

Clinical tests in common use for spasticity are largely tests which do not discriminate between the contribution of stretch reflexes and that of altered muscle mechanics (e.g., pendulum test and the Ashworth Scale; Fowler et al., 1997). Muscle co-contraction and stiffening of a limb can be taken as a sign of spasticity, but it might instead reflect a response to fear of falling (poor balance) or to lower limb collapse (weak lower limb muscles) and lack of skill. Similarly, an 'abnormal' movement pattern may not reflect spasticity but arise from muscle imbalance caused by the preferential use of stronger muscles and weakness or paralysis of others.
The functional significance of spasticity (as hyperreflexia) remains equivocal following stroke. Indeed, from studies so far it seems likely that reflex hyperactivity may make a relatively minor contribution to functional disability in many individuals following stroke (O'Dwyer et al., 1996). Nevertheless, it remains typical for spasticity to be considered the major impairment following stroke.

Understanding the contribution of adaptive structural and functional changes in muscles and knowing that these changes occur in response to muscle paralysis and weakness, compounded by disuse and physical inactivity, enables the development of strategies (such as active exercise, passive stretching, and orthoses) to decrease muscle stiffness and preserve the functional extensibility of muscles. At the same time, task- 
specific training (i.e., specific training of functional actions, such as walking, reaching, standing up) stimulates the regaining of motor control by training muscles to generate and time force at the necessary length and the appropriate relationship to each other for specific actions.

In some rehabilitation facilities, however, there is still a lack of acknowledgment of the profound effects on functional performance of muscle paralysis/weakness and physical and mental inactivity and, consequently, of the need for intensive exercise. In such facilities, individuals following stroke may have little or no opportunity to practice muscle-strengthening exercises, develop cardiovascular fitness and endurance, or train specifically for the motor actions they need to regain. It can still be typical for such patients to spend long periods of the day inactive in a passive and unchallenging environment (Mackey et al., 1996). It is interesting to note a recent paper (Macko et al., 1997) which demonstrated, after a post-stroke exercise program, an improvement not only in aerobic capacity (cardiovascular responses) but also in functional motor performance. Many other studies point to the improved fitness gained from an active exercise program (Potempa et al., 1996).

Following a lesion, physiological changes which could be called reparative take place in direct response to the lesion and the cellular damage incurred. In addition, the system begins to make adaptations to its altered state, and it is evident that these are driven by what the individual does, thinks, and experiences; i.e., use and experience may drive reorganizational and adaptive processes as they do in able-bodied individuals (Jenkins \& Merzenich, 1987; Kolb, 1995; Nudo et al., 1997; Liepert et al., 1998). If use and experience drive neural reorganization, so also do their conversedisuse, inactivity/immobility, and lack of meaningful experience (Nudo \& Grenda, 1992). The probability that what an individual does in rehabilitation after an acute brain lesion might affect, either positively or negatively, brain reorganization and neuromuscular responses, is driving some neurorehabilitation professionals to find the most effective interventions. A recent paper by Stefan et al. (2000) summarizes studies which have demonstrated the capability of the brain (e.g., at sensorimotor cortex and subcortical levels) to reorganize in response to injury. These studies focused on limb amputation, nerve transection, focal brain lesions; motor skill acquisition-motor learning; and repetition of simple movements-e.g., thumb movements. The authors point out that understanding the underlying mechanisms (and of course what drives them) is a necessary requirement for the development of strategies to promote recovery following brain damage.

In summary, the changes that take place at neuromotor, cognitive-perceptual, muscular, connective tissue, and cardiorespiratory levels are evidenced by

- Neural reorganization in response to lesion, use, experience, and activity (Kolb, 1995).

- Muscle changes, including increased muscle stiffness and length-associated changes (Thilmann et al., 1991; Carey \& Burghardt, 1993).

- Connective tissue changes such as contracture of joint capsule, ligaments (Dietz et al., 1991).

- At the behavioral or motor performance level-adaptive motor patterns reflecting muscle weakness/paralysis and resultant muscle imbalance (Delp et al., 1999).

- Decreased cardiovascular fitness and energy levels (Potempa et al., 1996; Macko et al., 1997).

- Depression, anxiety, helplessness

\section{BIOMECHANICS, EXERCISE, AND THE LEARNING OF MOTOR SKILL}

Research findings in biomechanics, exercise science, and motor-skill learning inform clinical practice by providing the knowledge necessary for 
planning the content of training and exercise programs and the measurement of performance. Increased understanding of the biomechanics of everyday actions has enabled the development of models of skilled motor performance which can guide movement analysis and the planning of intervention. The scientific study of skill acquisition, once largely the work of psychologists, overlaps into physiology and biomechanics as experimenters begin to focus on the neural mechanisms underpinning motor learning and on the mechanical changes taking place as motor performance becomes more skilled, i.e. more effective. Research into the physiology and mechanics of exercise examines the specificity of exercise and training, the effects of exercise on muscle and cardiovascular fitness.

Biomechanics tells us how able-bodied subjects perform an action in a consistent, effective, and efficient manner. It provides, therefore, information about essential spatio-temporal components of an action (i.e., muscle forces, angular displacements, and velocities), those critical components without which the action cannot be performed effectively. Studies of walking, stair walking, standing up and sitting down, reaching, and manipulation provide objective data about these actions against which a patient's performance can be compared.

The body of knowledge currently available is driving the development of biomechanical models of significant actions like walking, sit-to-stand, and reaching, which allow the development and testing of training and exercise protocols and guidelines (Dean et al., 1997, 2000; Texeira-Salmela et al., 1999). Science- and evidence-based protocols and guidelines will soon be more widely used in clinical practice as minimum criteria, affording the opportunity for multicenter trials to find the 'best practice'.

Biomechanical measurement tools are increasingly being used to test the effects of intervention. Note that the aim of exercise and training is not normalization as such, but optimum effectiveness of performance, and performance can be tested using complex tools, such as force plates and motion analysis systems, and simple ones, such as distance walked, time taken, stride length, grip strength, and distance reached in standing.

To regain skillful performance requires not only the ability to generate muscle forces but also the ability to time muscle activations to control complex musculoskeletal linkages. Both biomechanical and muscle studies consistently report movement patterns which are specific not only to the task being performed but also to the context in which the action is being carried out (e.g., Rutherford, 1988). These findings are consistent even in studies of complex postural adjustments (balance) (e.g., Nardone \& Schieppati, 1988). It is logical, therefore, to train individuals with movement disability by giving them the opportunity to practice these actions in the relevant contexts.

However, individuals with extreme weakness and lack of motor control may not be able to practice if the muscles critical to that activity are unable to produce and time the necessary force. There is evidence from work by Buchner et al. (1996) suggesting that, with marked weakness, the type of strengthening exercise given may not matter, provided it improves a muscle's forcegeneration. However, beyond a certain threshold of strength, exercise needs to be specific to the action being trained. In other words, when muscles are weak, methods such as electrical stimulation, weight-resisted open chain exercise, isometric contractions, and machine-assisted exercises can be given in the early stages as a means of improving the muscle's ability to contract. However, once muscle strength reaches a certain threshold, exercises should be biomechanically similar to actions being trained.

Let's say that we want to train a person to stand up and sit down after a stroke. This action requires lower limb extensor muscles which can lift over three times body mass and muscles which 
can cooperate with each other to control the forces produced. When muscles are very weak, exercises for quadriceps and other lower limb extensors are necessary to increase the force-generating ability of the muscles to a certain threshold. However, for transferring into improved performance of sit-tostand, exercises probably need to be closed-chain, produce sufficient resistance, and require a similar pattern of movement. Step-up exercises, being closed-chain (i.e., with a fixed distal segment, in this case with the foot on the step), enable practice of using lower limb extensor muscles to raise the body mass. In practice, such exercises are performed in a manner known to increase strength, e.g. 3 sets of 10 maximum repetitions. Sit-to-stand can itself be performed as a strengthening exercise, with seat height raised to make the action possible in an individual with muscle weakness and then lowered to increase resistance as strength and control improve. It is biomechanical studies of sit-to-stand which provide the information on which training is based. We know, for example,

a) the optimal foot placement for mechanical efficiency (Shepherd \& Koh, 1996),

b) that raising seat height decreases the muscle force requirements (Rodosky et al., 1987) and

c) that rotating the trunk/upper body forward at the hips potentiates lower limb extension (Pai \& Rogers, 1991; Shepherd \& Gentile, 1994).

It is becoming evident that transfer to actions which are dynamically similar can occur. For example, exercises which strengthen lower limb extensor muscles can transfer not only to improved sit-to-stand but also to improved speed of walking. The latter effect may be due to enhanced capacity to bear weight through stance phase (using ground reaction forces) and to propel the body mass forward at push off.

Strengthening exercises appear to have their effects by improving motor unit recruitment, the muscle's force-generating capacity, the timing of peak forces, and through developing neuromotor patterns of coordination through practice of the action, that is to say, motor learning. Active exercises also decrease muscle stiffness (Hagbarth et al., 1985) and reflex hyperactivity, if it is present (Butefisch et al., 1995).

This perspective in rehabilitation, which we first raised in 1982, is increasingly being seen to be critical where individuals must regain the ability to move effectively, i.e., to regain skill, in everyday actions. With stroke disability, however, the actions initially 'learned' by the individual, in the sheltered environment of hospital and rehabilitation center, may not be appropriate for life outside the institution. Once the acute phase of stroke is complete, the individual starts to move about as well as possible given the distribution of muscle weakness and any soft tissue adaptations which may have taken place. One way in which the subsequent restorative process can be viewed is as a process of learning which commences as soon as the person attempts an action. If the movement pattern is reasonably effective, it will be repeated and learned. If it is ineffective, alternative ways may be found (e.g., use the other hand) or the person may give up that action (e.g., replacing walking with wheelchair locomotion). Moving effectively in the non-demanding hospital environment is not, however, the same as moving about in the outside world. Walking slowly using a 4-point cane or propelling oneself in a one-arm drive wheelchair may be relatively effective in hospital, but, once discharged home, the individual needs the ability to stand up from different chairs, walk the necessary distances, cross the road at traffic lights, and so on. If this is not possible, less and less walking will be done, and there is evidence that some individuals deteriorate in functional abilities after they are discharged (Wade et al., 1992).

Although the action being attempted, walking for example, is one in which the individual was previously skilled, regaining the ability to walk again in the presence of considerable alteration to 
the motor control system is probably akin to learning a new action and developing skill. Rosenbaum (1991) has pointed out that movement becomes more skilled with learning, and this is probably due to improvements in timing, tuning, and coordinating muscle activations. Training walking should, therefore, include exercises to strengthen weak muscles, to preserve muscle length, plus the practice of walking, if necessary with an aid such as mobile walking machine with harness to support some body weight or to prevent a fall. Walking on a treadmill may be effective in 'forcing' the reciprocal action of lower limbs, hip extension, and ankle dorsiflexion at the end of stance phase, and in potentiating hip flexion and ankle plantarflexion. A harness (taking 30\% body weight) may be necessary early in training when lower limb muscles are too weak to support $100 \%$ body weight (Hesse et al., 1995). However, intensive exercise and electrical stimulation to improve the activation of weak or paralyzed lower limb muscles may also be critical in the early stages.

We do not yet know enough about what is learned, what takes place at the neural level, and how best to drive learning in disabled individuals. However, we do know a great deal about how ablebodied individuals learn to perform effectively and to acquire skill in a particular motor action (Magill, 1998; Gentile, 2000), and we can use these methods in rehabilitation. It is well known, for example, that motor learning and developing skill require practice with concrete goals and objective feedback about effectiveness. The learner must have the opportunity to practice actively and to understand the importance of frequent repetitions.

\section{CONCLUSION}

Rehabilitation to improve functional motor performance is increasingly becoming focused on exercise and training-exercise to improve strength and timing of muscle activations and cardiovascular fitness and training to gain optimal skill in functional actions. The methods used are driven by current knowledge in many fields, many of which are outside the traditional knowledge of rehabilitation professionals. Clinical and experimental liaisons are being formed, not only between physiotherapists and physicians but also with biomechanists, physiologists, psychologists, exercise physiologists, and computer scientists.

However, major changes still need to take place in clinical practice to take account of the patient's needs as an active learner and the need to increase practice opportunity and time spent in exercising to optimize muscle strength and in training. Therapists are beginning to move away from reliance on the one-to-one, hands-on form of therapy delivery and are making use of circuit training and group exercise and training programs. More use is being made of technological advances, such as interactive computerized systems, exercise machines giving motivational feedback, supportive walking systems, and treadmills (Hesse et al., 1995; Shepherd \& Carr, 1999). Conceptual advances such as the use of forms of constraint to 'force' the required muscle action are being shown to be effective (Taub et al., 1993). Exercise and training sessions are being carried out throughout the day, thereby increasing the time spent in practice. In these programs, emphasis is placed on physical training and exercise and on skill training, stressing cognitive engagement and practice, gaining strength, control, and fitness. There is increasing evidence that such methods can be effective in improving functional performance in elderly individuals, including those with stroke (e.g., Sherrington \& Lord, 1997; Dean et al., 2000). Some health professionals, however, remain locked into old-fashioned methods and are reluctant or unable to change. The continuing dominance of Bobath therapy (e.g., Davies, 1990) and the acceptance of this by physicians for over half a 
century, despite lack of an up-to-date scientific rationale and evidence of effective functional outcomes, is hard to understand given the relevance of modern scientific knowledge to neurorehabilitation and the number of published studies reporting positive effects of methods based on such knowledge.

Since it is evident that task-specific training has the potential to drive brain reorganization toward more optimal functional performance, it is critical to utilize training methods most likely to have a positive impact on this process and shown to be effective. In reviewing the literature, a sense of optimism comes the from the evidence presented in many recent studies. These studies illustrate the potential for improved outcomes with more modern active and performance-oriented methodologies. Of major interest to neurorehabilitation will be the results of research in which training methods are tested for their effects on functional performance by measurements of biomechanical change, measurements of organizational changes in the brain and spinal cord, post-discharge motor effectiveness, and patient satisfaction.

\section{ACKNOWLEDGEMENT}

The author wishes to acknowledge the contribution of Dr Janet Carr to this paper, which represents theoretical work carried out in joint collaboration.

\section{REFERENCES}

Buchner DM, Larson EB, Wagner EH, Koepsell TD, de Lateur BJ. 1996. Evidence for a non-linear relationship between leg strength and gait speed. Age Ageing 25: 386-391.

Butefisch C, Hummelsheim H, Mauritz K-H. 1995. Repetitive training of isolated movements improves the outcome of motor rehabilitation of the centrally paretic hand. J Neurol Sci 130: 59-68.

Carey JR, Burghardt TP. 1993. Movement dysfunction following central nervous lesions: A problem of neurologic or muscular impairment. Phys Ther 73: 538-547.

Carr JH, Shepherd RB. 1998. Neurological Rehabilitation. Optimizing Motor Performance, Oxford, UK: Butterworth Heinemann; 350.

Carr JH, Shepherd RB. 2000. A motor learning model for rehabilitation. In: Carr JH, Shepherd RB, eds, Movement Science. Foundations for Physical Therapy in Rehabilitation, 2nd ed. Gaithersburg, Maryland, USA: Aspen Publishers; 33-110.

Davies P. 1990. Right in the Middle. Selective Trunk Activity in the Treatment of Adult Hemiplegia Berlin-Heidelberg-New York: Springer-Verlag; 514.

Dean C, Shepherd RB. 1997. Task-related training improves performance of seated reaching tasks following stroke: A randomised controlled trial. Stroke 28: 722-728.

Dean C, Richards CL, Malouin F. In press. Taskrelated circuit training improves performance of locomotor tasks in chronic stroke. A randomized controlled pilot trial. Arch Phys Med Rehab.

Delp SL, Hess WE, Hungerford DS, Jones LC. 1999. Variation of rotation moment arms with hip flexion. J Biomechanics 32: 493-501.

Dietz V, Ketelson UP, Berger SC. 1986. Motor unit involvement in spastic paresis: Relationship between leg muscle activation and histochemistry. J Neurol Sci 75: 89-103.

Dietz V Trippel M, Berger W. 1991. Reflex activity and muscle tone during elbow movements in patients with spastic paresis. Ann Neurol 30: 767-779.

Farmer SF, Swash M, Ingram DA, Stephens JA. 1993. Changes in motor unit synchronization following central nervous lesions in man. $J$ Neurophysiol (London) 463: 83-105.

Fowler V, Canning CG, Carr JH, Shepherd RB. 1997. The effect of muscle length on the pendulum test. Arch Phys Med Rehab 79: 169-171.

Gentile AM. 2000. Skill acquisition: Action, movement and neuromotor processes. In: Carr JH, Shepherd RB, eds, Movement Science. Foundations for Physical Therapy in Rehabilitation. Gaithersburg, Maryland, USA: Aspen Publishers, Inc.; 111-188.

Hagbarth K-E, Hagglund JV, Norkin M. 1985. Thixotropic behaviour of human finger flexor muscles with accompanying changes in spindle and reflex responses to stretch. J Physiol 368: 323-342. 
Hesse S, Bertelt C, Jahnke MT, Schaffrin A, Baake P, Malezic M, et al. 1995. Treadmill training with partial body weight support compared with physiotherapy in non-ambulatory hemiparetic stroke patients. Stroke 26: 976-981.

Jenkins WM, Merzenich MM. 1987. Reorganisation of neocortical representations after brain injury: A neurophysiological model of the bases of recovery from stroke In: Seil FJ, Herbert E, Carlson, BM, eds, Progress in Brain Research, vol. 71. New York, NY, USA: Elsevier Science; 249-266.

Kolb B. 1995. Brain, Plasticity and Behavior. Mahwah, New Jersey, USA: Lawrence Erlbaum; 194.

Lance JW. 1980. Symposium synopsis. In: Feldman RG, Young RR, Koella WP, eds, Spasticity Disordered Motor Control. Chicago, Illinois, USA: Year Book Medical Publishers; 485-495.

Lance JW. 1990. What is spasticity? [Letter] Lancet 335: 606.

Liepert J, Miltner WHR, Bauder H, Sommer M, Dettmers C, Taub E, et al. 1998. Motor cortex plasticity during constraint-induced movement therapy in stroke patients. Neurosci Lett 250: 5-8.

Macko RF, DeSouza CA, Tretter BS, Silver KH, Smith GV, Anderson PA, et al. 1997. Treadmill aerobic exercise training reduces the energy expenditure and cardiovascular demands of hemiparetic gait in chronic stroke patients. Stroke 28: 326-330.

Mackey F, Ada L, Heard R, Adams R. 1996. Stroke rehabilitation: Are highly structured units more conducive to physical activity than less structured units? Arch Phys Med Rehab 77: 1066-1070.

McComas AJ. 1993. Human neuromuscular adaptations that accompany changes in activity. Med Sci Sports Exercise 26: 1498-1509.

Magill RA. 1998. Motor Learning Concepts and Applications. New York, NY, USA: McGraw-Hill; 326.

Nardone A, Schieppati M. 1988. Postural adjustments associated with voluntary contraction of leg muscles in standing man. Exp Brain Res 30: 13-24.

Nudo R, Grenda R. 1992. Reorganization of distal forelimb representations in primary motor cortex of adult squirrel monkeys. Soc Neurosci Abstr 18: 216.

Nudo RJ, Wise BM, SiFuentes F, Milliken GW. 1997. Neural substrates for the effects of rehabilitative training on motor recovery after ischaemic infarct. Neural Network [Comment] 1: 121-126.

O'Dwyer NJ, Ada L, Neilson PD. 1996. Spasticity and muscle contracture following stroke. Brain 119:
1737-1749.

Pai Y, Rogers MW. 1991. Segmental contribution to total body momentum in sit-to-stand. Med Sci Sports Exercise 23: 225-230.

Potempa K, Braun LT, Tinknell T, Popovich J. 1996. Benefits of aerobic exercise after stroke. Sports Med 21: 337-346.

Rodosky MV, Andriacchi TP, Andersson GBJ. 1989. The influence of chair height on lower limb mechanics during rising. J Orthoped Res 7: 266-271.

Rosenbaum DA. 1991. Human Motor Control. New York, NY, USA: Academic Press; 411.

Rutherford OM. 1988. Muscular coordination and strength training. Implications for injury rehabilitation. Sports Med 5: 196-202.

Shepherd RB, Carr JH. 1999. Treadmill walking in neurorehabilitation. Neurorehab Neural Repair 13: 171-173.

Shepherd RB, Gentile AM. 1994. Sit-to-stand: Functional relationships between upper body and lower limb segments. Human Movement Sci 13: 817-840.

Shepherd RB, Koh HP. 1996. Some biomechanical consequences of varying foot placement in sit-tostand in young women. Scandinavian J Rehab Med 28: 79-88.

Sherrington C, Lord SR. 1997. Home exercise to improve strength and walking velocity after hip fracture: A randomized controlled trial. Arch Phys Med Rehab 78: 208-212.

Stefan K, Kunesch E, Cohen LG, Benecke R, Classen J. 2000 . Induction of plasticity in the human motor cortex by paired associative stimulation. Brain 123 : 572-584.

Tang A, Rymer WZ. 1981. Abnormal force-EMG relations in paretic limbs in hemiparetic human subjects. J Neurol Neurosurg Psychiatry 44: 690698.

Taub E, Miller NE, Novack TA, Cook EW, Fleming WC, Nepomuceno CS, et al. 1993. Technique to improve chronic motor deficit after stroke. Arch Phys Med Rehab 74: 347-354.

Texeira-Salmela LF, Olney SJ, Nadeau S. 2000. Muscle strengthening and physical conditioning to reduce impairment and disability in chronic stroke survivors. Arch Phys Med Rehab 80: 1211-1218.

Thilmann AF, Fellows SJ, Rose HF. 1991. Biomechanical changes at the ankle joint after stroke. J Neurol Neurosurg Psychiatry 54: 134-139.

Wade DT, Collen FM, Robb GF. 1992. Physiotherapy intervention late after stroke and mobility. $\mathrm{Br}$ Med J 304: 609-613. 

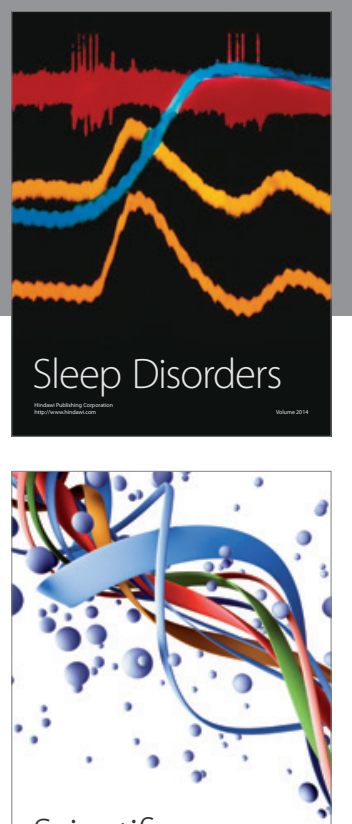

Scientifica
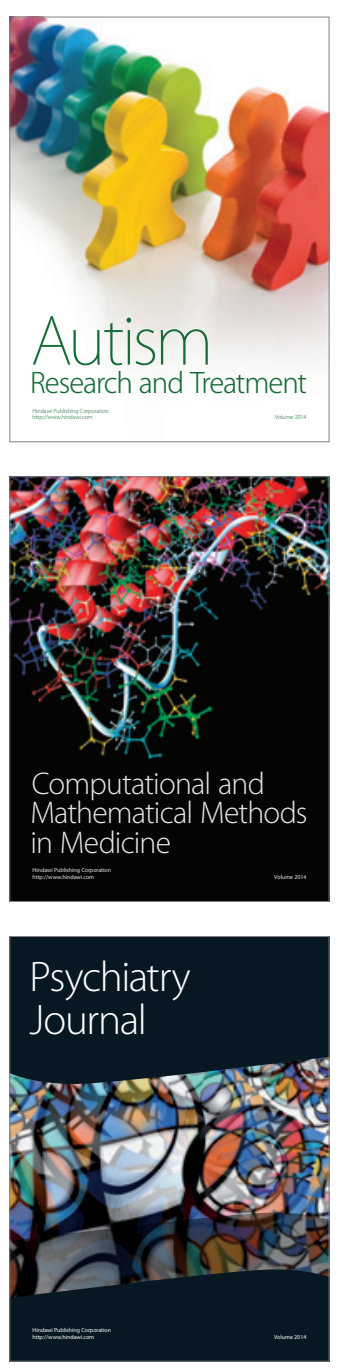
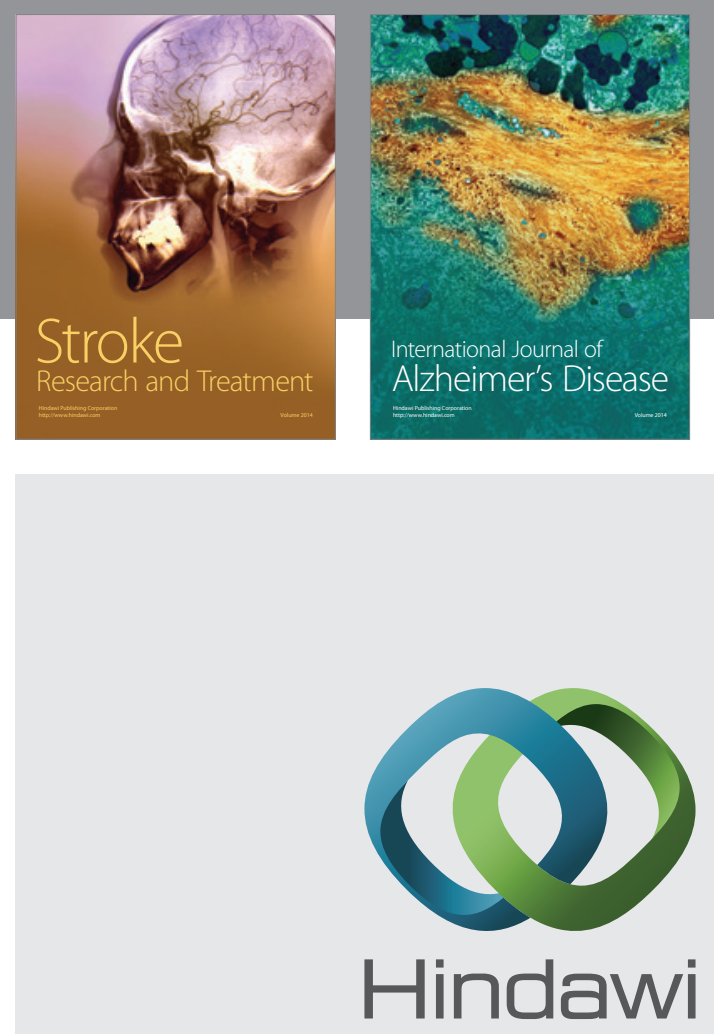

Submit your manuscripts at

http://www.hindawi.com
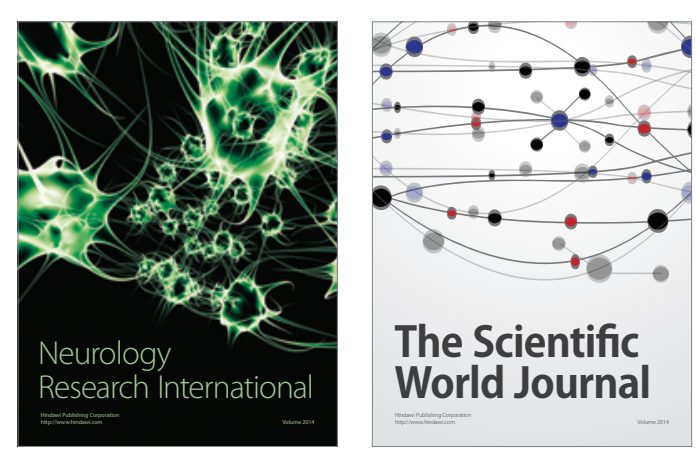

The Scientific World Journal

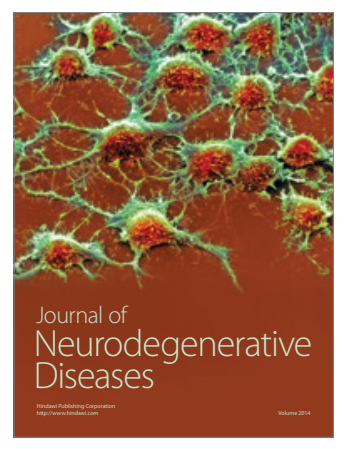

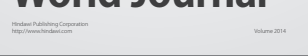

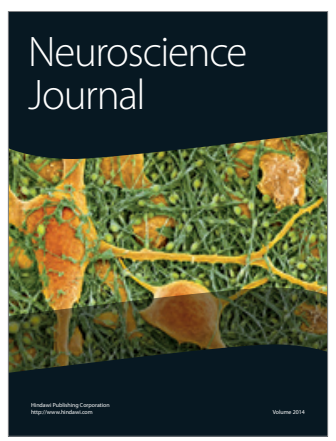

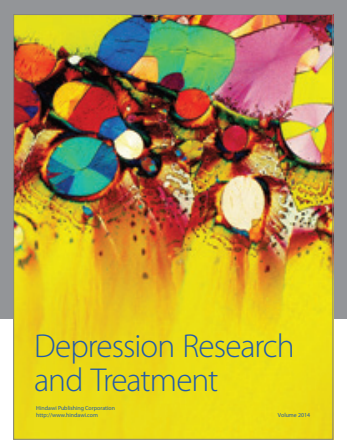
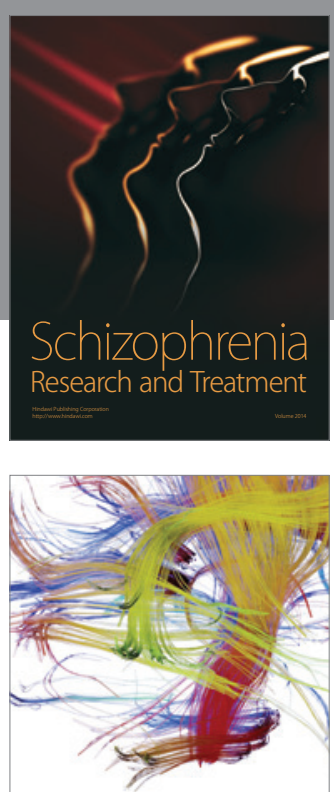

Brain Science

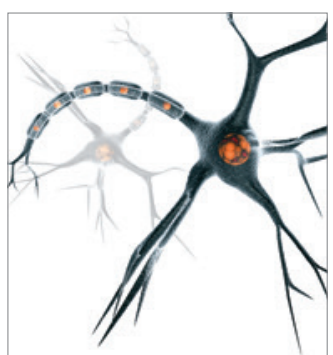

Neural Plasticity
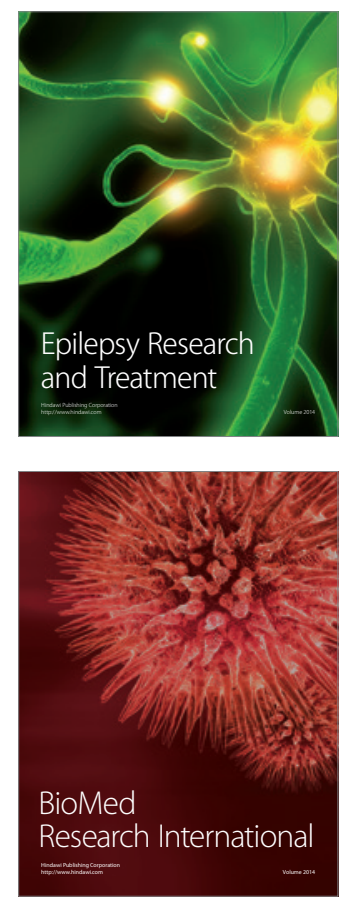

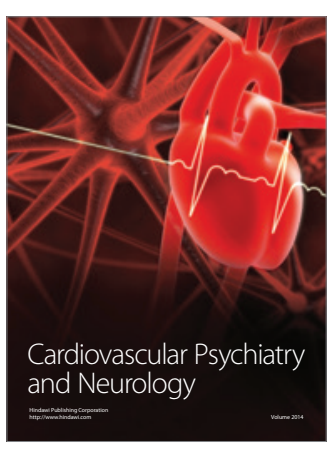

Parkinson's

Disease
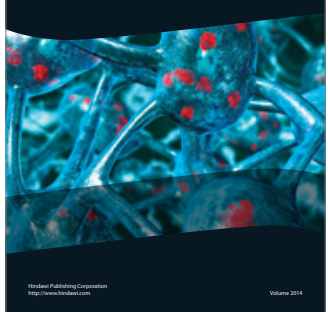